\title{
Synthesis of Brown Inorganic Pigments with Spinel Structure from the Incorporation of Spent Alkaline Batteries
}

\author{
Letícya Jéssica Almeida ${ }^{a}$,Edson Cezar Grzebielucka ${ }^{a}$, Sandra Regina Masetto Antunes ${ }^{a}$, \\ Christiane Philippini Ferreira Borges ${ }^{a}$, André Vitor Chaves de Andrade, \\ Éder Carlos Ferreira de Souza ${ }^{a *}$ (D) \\ ${ }^{a}$ Universidade Estadual de Ponta Grossa (UEPG), Departamento de Química, Ponta Grossa, PR, Brasil
${ }^{b}$ Universidade Estadual de Ponta Grossa (UEPG), Departamento de Física, Ponta Grossa, PR, Brasil
}

Received: September 12, 2019; Revised: November 19, 2019; Accepted: January 13, 2020

\begin{abstract}
In this work, inorganic pigments were synthesized by solid state reaction, from the incorporation of components of exhausted alkaline batteries. For this, after disassembling the batteries, the components were subjected to water leaching, milling and heat treatment at high temperatures with an addition of $33 \%$ (in mol) commercial or recovered from own alkaline batteries anodes zinc oxide. The obtained pigments were characterized by X-ray diffractometry, scanning electron microscopy, laser diffraction particle size, and UV-Vis diffuse reflectance spectroscopy. It was concluded that incorporation of the components of batteries generally yielded brown pigments with a structure of the spinel type $\mathrm{ZnMn}_{2} \mathrm{O}_{4}$. SEM and particle size distribution analyses show that the addition of $\mathrm{ZnO}$ leads to a reduction in average grain size of the powders. The pigments when applied to color ceramic enamels, polymers and paints show good performance in the coloring of these products, with potential for commercial application.
\end{abstract}

Keywords: Spinels, solid state synthesis, colour, pigments, recycle.

\section{Introduction}

Economic development, technological advancements, and population growth have influenced mass changes in lifestyle and human consumption. As a result, there has been a significant increase in the generation of solid residues, mainly from electronics residues such as batteries ${ }^{1}$.

It is estimated that Brazil produces about 1.2 billion units of batteries annually, a level far below that of countries such as China, where production is estimated at 15 billion units per year ${ }^{2}$.

Such large quantities of batteries have produced residues composed of toxic metals considered to be hazardous to human health and the environment. In this way, the final disposal of spent batteries represents a growing environmental problem, since they are still deposited in landfills and incinerated, instead of being collected and recycled ${ }^{1,3,4}$.

There are two basic types of batteries: primary and secondary batteries. Primary batteries are essentially non-rechargeable and their chemical reactions are irreversible. Among the many primary batteries commercialized, the most noteworthy are zinc/manganese dioxide and zinc alkaline. Alkaline batteries are composed of a porous zinc as the anode, with manganese dioxide as the cathode and a concentrated aqueous potassium hydroxide $(\mathrm{KOH})$ solution as the electrolyte ${ }^{5,6}$.

It is known that natural reserves of zinc will be exhausted in about 20-40 years. However, this material, as well as manganese, could be recovered from batteries such as the

*e-mail: ecfsouza@uepg.br alkaline type, as a secondary source of raw materials. It is possible that the solution to the question of spent batteries and other spent electronic materials is the recycling of these materials $\mathrm{s}^{2,7}$. One of the possibilities of recycling these elements is in the production of inorganic pigments.

Pigments are materials of great importance for many productive sectors, especially for the coating industry where color is a fundamental parameter for the development of new products. In these sectors, the search for new coloring materials is constant, with a focus on cost reduction, environmental suitability and innovation in colors and processes ${ }^{8}$.

The literature reports several works in which residues were used as raw materials for pigment synthesis. The work of Milanez et al. ${ }^{9}$, for example, reports the obtaining of iron, zinc and manganese inorganic pigments from the incorporation of electroplating waste. Marcello et al. ${ }^{10}$, in turn, present good results for the partial replacement of a commercial pigment from the incorporation of sludge from the treatment of coal mine waste. Fiuza et al. ${ }^{11}$ present promising results for spinel-like pigments from the addition of chromium oxide $\left(\mathrm{Cr}_{2} \mathrm{O}_{3}\right)$ to the electrolytic paste of zinc-carbon batteries.

In this context, the objective of the present work was the synthesis of inorganic pigments through solid state reaction, from incorporation of the components of spent alkaline batteries. In this case, the anode was used as a source of zinc oxide and the cathode as a source of manganese oxide to produce brown inorganic pigments with composition based in $\mathrm{ZnMn}_{2} \mathrm{O}_{4}$ spinel. 


\section{Experimental Procedure}

\subsection{Synthesis of pigments}

To begin with, depleted batteries (type AA) were opened and their constituents separated manually. The alkaline battery cathodes were oven dried and sieved to remove coarse residues. These cathodes compounds were used as sources of manganese dioxide $\left(\mathrm{MnO}_{2}\right)$. The anodes compounds were recovered and used as a source of zinc oxide $(\mathrm{ZnO})$.

After separation, the battery cathodes were milled and homogenized in a ball mill with distilled water for $4 \mathrm{~h}$. The milling of components was carried out in a $250 \mathrm{ml}$ polypropylene bottle (diameter $6 \mathrm{~cm}$ and length $13 \mathrm{~cm}$ ) with cylindrical grinding elements of magnesia-stabilized zirconia ( $1 \mathrm{~cm}$ in diameter, $1 \mathrm{~cm}$ in height and weight of $3 \mathrm{~g})$. After washing, the resulting materials were oven dried at $100{ }^{\circ} \mathrm{C}$ for $12 \mathrm{~h}$. The battery anodes were processed similarly.

After recovery of the alkaline battery components, the cathode material was heat treated at $800{ }^{\circ} \mathrm{C}$ for $2 \mathrm{~h}$ in a JUNG muffle furnace in a static air atmosphere to obtain the $\mathrm{ZnMn}_{2} \mathrm{O}_{4}$ phase of interest. The resulting powders were deagglomerated in a 200 mesh $(75 \mu \mathrm{m})$ sieve in order to have a larger contact surface, favoring the solid-state reaction. These samples were named CAT 800 . The cathode material was also heat treated at $1200^{\circ} \mathrm{C}$ for $2 \mathrm{~h}$ in a JUNG muffle furnace in a static air atmosphere to compare with the pigments obtained at this temperature. This sample was named CAT 1200.

To adjust the stoichiometry of the phase of interest $\left(\mathrm{ZnMn}_{2} \mathrm{O}_{4}\right), \mathrm{ZnO}$ was added to the CAT 800 samples in proportion of $33 \%$ (in mol). Two differente sources of $\mathrm{ZnO}$ were used: commercial zinc oxide (DYNAMIC, 99.0\%), or zinc oxide recovered from the anode of the batteries. These systems were ground and homogenized in a ball mill for $2 \mathrm{~h}$ with the addition of $30 \mathrm{~mL}$ of isopropyl alcohol (DYNAMIC, P.A). The powders were oven dried and thermally treated at $1200{ }^{\circ} \mathrm{C} / 2 \mathrm{~h}$ in a JUNG muffle furnace in a static air atmosphere. The resulting materials were deagglomerated in a 325 mesh sieve $(45 \mu \mathrm{m})$. The obtained pigments were named PAZC33 (obtained from commercial ZnO) or PAZR33 (obtained from battery- recovered $\mathrm{ZnO}$ ). All syntheses were performed in triplicate. The a, b or c indices in Figures and Tables represents the replicates of the syntheses.

\subsection{Application of pigments in ceramics enamels, paints and polymers}

The vitreous enamels were prepared from a mixture of 5\% $(\mathrm{w} / \mathrm{w})$ pigment, $95 \%(\mathrm{w} / \mathrm{w})$ low-temperature frit (M.P. $\left.850{ }^{\circ} \mathrm{C}\right)$ and about $0.5 \mathrm{~mL}$ of distilled water. The obtained mixtures were applied to the surface of ceramic pieces with a thickness of $0.05 \mathrm{~mm}$. Finally, the enamels were heat treated at $850^{\circ} \mathrm{C}$ at a heating rate of $10^{\circ} \mathrm{C} / \mathrm{min}$ with a $20 \mathrm{~min}$ holding time in a JUNG muffle furnace.

The paint samples were obtained through a 1:1 mixture of commercial white paint (Suvinil, water-based) and distilled water, with the addition of $5 \%(\mathrm{w} / \mathrm{w})$ pigment. The mixtures were applied to the surface of smooth glass slides (GlassTécnica) in three coats with the aid of a brush and dried in an oven at $100{ }^{\circ} \mathrm{C}$.
The polymers were prepared by staining methyl polymethacrylate with $5 \%(\mathrm{w} / \mathrm{w})$ pigment relative to the total weight of the blends. After curing, the polymers were transferred to a steel mold being shaped into a chip $13 \mathrm{~mm}$ in diameter. Uniaxial pressing of the pellets was carried out in a Vonder hydraulic press with a pressure of $75 \mathrm{MPa}$ applied for $2 \mathrm{~min}$. The procedures used for pigments application were adapted from reference Vishnu et al. ${ }^{12}$ and Müller et al. ${ }^{13}$.

\subsection{Samples characterization}

The analysis of the chemical elements present in the raw materials was determined by an X-ray fluorescence spectrometer (Rigaku Primus II). The analyses were performed in a fast scan mode (EZ ANALYZE) from boron to uranium in pressed pellets.

The crystalline phase of the samples were determined by X-ray diffractometry in a diffractometer (Shimadzu XRD $6000)$ with $\mathrm{Cu} \mathrm{K} \alpha$ radiation source $(\lambda=1.5406 \AA)$ operating at $40 \mathrm{kV}$ and $30 \mathrm{~mA}$. The analyses were performed in the range of $3.0^{\circ}$ to $100.0^{\circ}(2 \theta)$, with a scan speed of $2.0^{\circ} / \mathrm{min}$. The slits of divergence and scattering were $1.00^{\circ}$, and the receiving slit, $0.30 \mathrm{~mm}$.

The morphological properties of the samples were determined by field-emission scanning electron microscope (FE-SEM, TESCAN Mira 3 LM). The samples were previously metalized with a gold layer of approximately $3 \mathrm{~nm}$. The particle size distribution of the samples was determined by laser diffraction in a laser granulometer (CILAS 920) in the range of $0.3 \mu \mathrm{m}$ to $400 \mu \mathrm{m}$. For the measurements, $0.2 \mathrm{~g}$ of powder sample was dispersed in distilled water without the addition of dispersing agents. The sample dispersion was performed by an ultrasonic bath before and during the analyses to avoid agglomeration of the particles.

The optical properties of the powder and applied pigments were determined by diffuse reflectance spectroscopy in the UV-Vis region (Cary ${ }^{\circledR} 50$ Conc UV-Vis) spectrophotometer (Varian, Inc.) with a Barrelino ${ }^{\mathrm{TM}}$ diffuse reflectance probe. The equipment was calibrated at $100 \%$ reflectance with a barium sulfate standard $\left(\mathrm{BaSO}_{4}\right)$.

\section{Results and Discussion}

\subsection{Characterization of the battery components}

Table 1 shows the elemental chemical composition, in \% weight, of the CAT 800 sample. No elements with a percentage $<1 \%$ by weight were identified. From the analysis of Table 1 , it was possible to observe that the CAT 800 sample consisted mainly of zinc, manganese, and oxygen and could therefore be used as a viable source of compounds for synthesis of zinc manganites compounds. There was also a considerable reduction in the carbon percentage from $13.5 \%$ (in raw cathode) to $1.02 \%$ (in CAT 800 ), this reduction being associated with the removal of graphite during the heat treatment. Carbon is added to change the electrical conductivity of manganese oxide in batteries.

Table 1 also shows the elemental chemical composition, in \% weight, of the zinc oxide recovered from the anodes of the alkaline batteries after the procedure described in Experimental. No elements with a percentage $<1 \%$ by weight were identified. From the analysis of Table 1, it 
Table 1. Elemental chemical composition determined by wavelength dispersive X-ray fluorescence (WD-XRF), in \% weight, of the CAT 800 and CAT 1200 samples after heat treatment at $800^{\circ} \mathrm{C}$ and $1200{ }^{\circ} \mathrm{C}$, respectively. Results for zinc oxide recovered from the alkaline batteries' anodes are also shown.

\begin{tabular}{cccc}
\hline Elements & CAT 800 (\% weight) & CAT 1200 (\% weight) & $\begin{array}{c}\text { Alkaline batteries anode (ZnO) } \\
\text { (\% weight) }\end{array}$ \\
\hline $\mathrm{C}$ & 1.02 & - & 1.34 \\
\hline $\mathrm{K}$ & 1.91 & 4.20 & - \\
\hline $\mathrm{Mn}$ & 56.6 & 55.0 & 75.1 \\
\hline $\mathrm{Zn}$ & 13.7 & 11.2 & 22.8 \\
\hline $\mathrm{O}$ & 25.9 & 28.2 & 0.76 \\
\hline minors & 0.87 & 1.40 & \\
\hline
\end{tabular}

was possible to observe that the zinc oxide recovered from the anodes was composed mainly of zinc and oxygen and for this reason could be used as an alternative raw material for pigment synthesis, after leaching procedure described in experimental, in the substitution of commercial $\mathrm{ZnO}$.

Theoretical calculation of the molar ratios from XRF data (Table 1) revealed that the present stoichiometry for sample CAT 800 was $\mathrm{Zn}_{1.00} \mathrm{Mn}_{4.91} \mathrm{O}_{7.70}$ and $\mathrm{Zn}_{1.00} \mathrm{Mn}_{5.84} \mathrm{O}_{10.28}$ for sample CAT 1200. These compositions would allow for the formation of the phase of interest, $\mathrm{ZnMn}_{2} \mathrm{O}_{4}$, still leaving an excess of manganese and oxygen in its composition. The excess of these elements ( $\mathrm{Mn}$ and $\mathrm{O}$ ) could be associated with the presence of secondary phases such as manganese dioxide $\left(\mathrm{MnO}_{2}\right)$ or the formation of oxygen-deficient manganese phases (as we confirmed in XRD analyses). The increase in heat treatment temperature did not lead to the disappearance of the observed secondary phase. To decrease the secondary phase $\left(\mathrm{MnO}_{2}\right)$ concentration and adjust the stoichiometry to obtain the desired $\mathrm{ZnMn}_{2} \mathrm{O}_{4}$ phase, $\mathrm{ZnO}$ was added to CAT 800, leading to the formation of $\mathrm{ZnMn}_{2} \mathrm{O}_{4}$ majoritary phase. The complementary $\mathrm{ZnO}$ in this work came from two different sources, commercial $\mathrm{ZnO}$ or recovered $\mathrm{ZnO}$ from the alkaline battery anodes.

Figure 1 shows the X-ray diffractogram of the samples CAT 800 after heat treatment at $800{ }^{\circ} \mathrm{C}$ and CAT 1200 after heat treatment at $1200{ }^{\circ} \mathrm{C}$. The results of the XRD indicated that the samples showed peaks referring to the $\mathrm{ZnMn}_{2} \mathrm{O}_{4}$ phase with a tetragonal system and with I41/amd (JCPDF 24-1133). In addition, the presence of $\mathrm{MnO}_{2}$ as a secondary phase with a tetragonal system and with $I 4 / \mathrm{m}$ (JCPDF 72-1982) was observed in both samples obtained from different thermal treatment temperatures. These results confirm the stoichiometry obtained by XRF (Table 1). The presence of $\mathrm{MnO}_{2}$ made it difficult (but not impossible) to apply the CAT 800 sample as a ceramic pigment, since, at high temperatures, $\mathrm{MnO}_{2}$ can be reduced to manganese oxide III $\left(\mathrm{Mn}_{2} \mathrm{O}_{3}\right)$, releasing gases. The emission of gases in the ceramic glaze may produce defects in the surface of the enamel. For this reason, the pure cathode was not the most suitable material for the enameling of ceramic pieces. This confirms the need for stoichiometry adjustment by the addition of $\mathrm{ZnO}$.

Figure 2 shows the X-ray diffractogram of the zinc oxide recovered from the exhausted alkaline battery anodes after the procedure described in Experimental. The analysis of the diffractogram of the Figure 2 revealed the presence of characteristic peaks of a single phase of zinc oxide with a hexagonal system (JCPDF 36-1451). No secondary phases were observed.

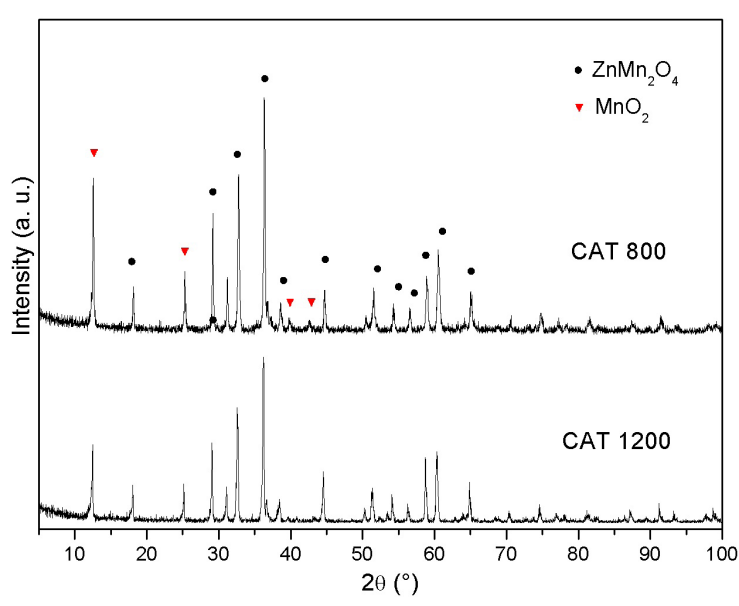

Figure 1. X-ray diffractogram of the of the CAT 800 and CAT 1200 samples after heat treatment at $800{ }^{\circ} \mathrm{C}$ and $1200{ }^{\circ} \mathrm{C}$, respectively.

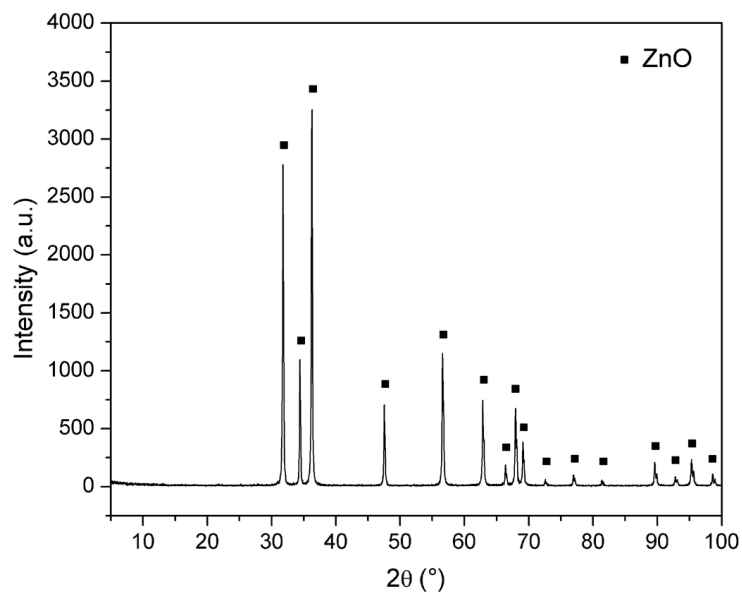

Figure 2. X-ray diffractogram of the leached zinc oxide recovered by the spent alkaline battery anodes.

Figure 3 a shows the micrographs obtained by FE-SEM of the CAT 800 sample after heat treatment at $800{ }^{\circ} \mathrm{C}$. The micrographs revealed that the sample CAT 800 was composed by agglomerates of particles of different sizes. The agglomerates observed presented irregular forms, resulting from the agglomeration of smaller particles. Figure 3B shows the particle size distribution (PSD) of the CAT 800 sample. The PSD analysis revealed that the CAT 800 sample was composed of particles with diameters between $0.3 \mu \mathrm{m}$ and 

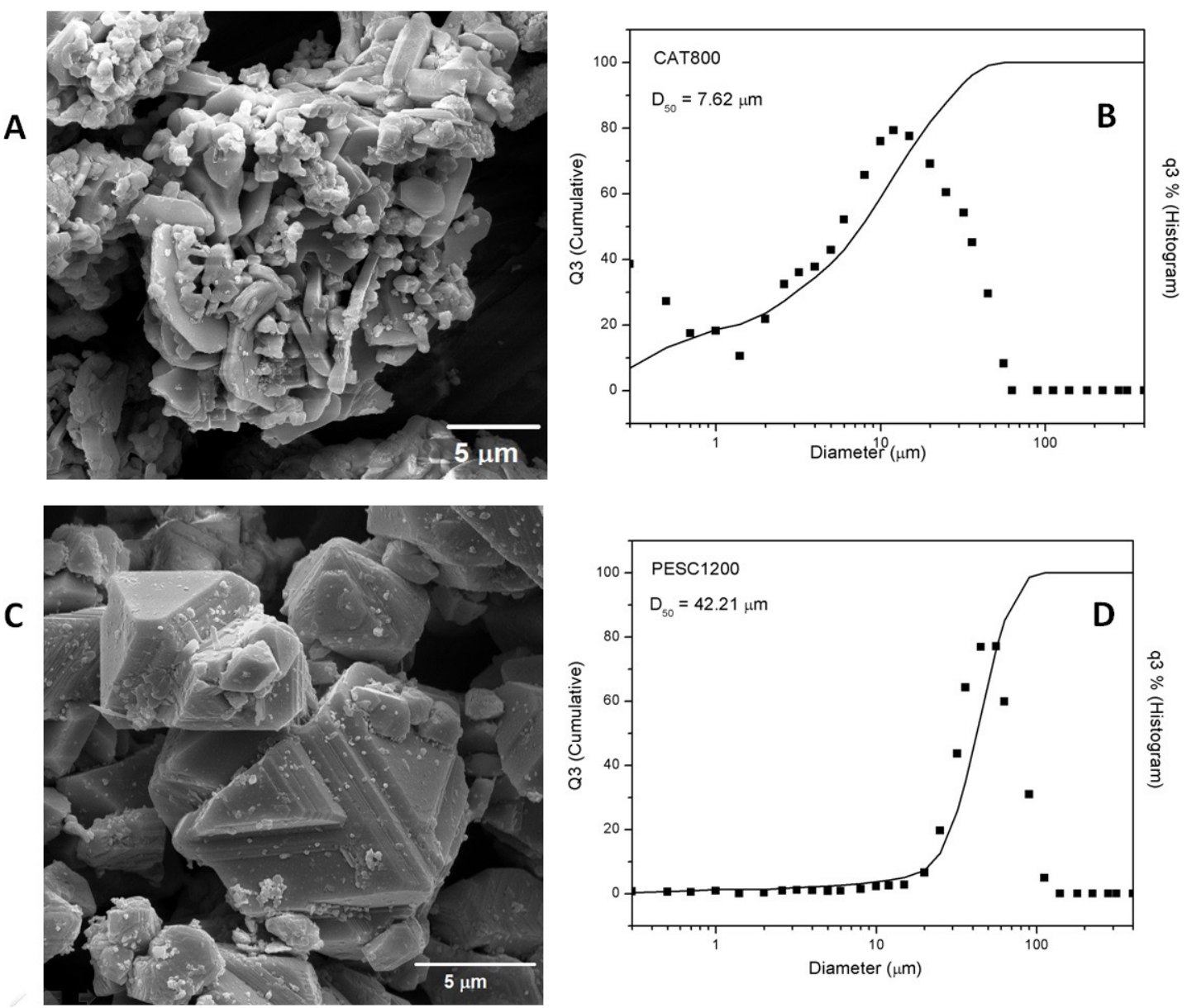

Figure 3. (A) Micrographs obtained by FE-SEM and (B) Particle size distribution of the CAT 800 sample, after heat treatment at $800^{\circ} \mathrm{C}$. (C) Micrographs obtained by FE-SEM and (D) Particle size distribution of the CAT 1200 sample, after heat treatment at $1200^{\circ} \mathrm{C}$.

$65 \mu \mathrm{m}$, with a mean particle diameter of $7.62 \mu \mathrm{m}$, a result that corroborated with the images obtained by the technique FE-SEM.

When the sample was heat treated at $1200^{\circ} \mathrm{C}$ (Figure 3C), it was observed that there was an increase in the size of the agglomerates, indicating that a powder sintering process occurred. The PSD analysis (Figure 3D) revealed that the CAT 1200 sample was composed of particles with diameters between $20 \mu \mathrm{m}$ and $100 \mu \mathrm{m}$, with a mean particle diameter of $42.21 \mu \mathrm{m}$. This particle size is outside the optimum range for application as a pigment ${ }^{14}$ and an additional grinding process would be required. The particle size associated with the fact that for the heat-treated material at $1200^{\circ} \mathrm{C}$ showed no change in the composition of crystalline phases indicates that this sample is not viable as a pigment. Therefore, we opted for the addition of $\mathrm{ZnO}$ to the sample CAT 800 for the formation of the phase of interest.

\subsection{Characterization of pigments}

X-ray diffractograms of the PAZC33 and PAZR33 powder pigments with addition of $\mathrm{ZnO}$ from different sources (commercial or recycled) to the sample CAT800 and heat treatment at $1200^{\circ} \mathrm{C}$ are shown in Figure 4. The analysis of Figure 4 indicated the presence of the tetragonal phase of the

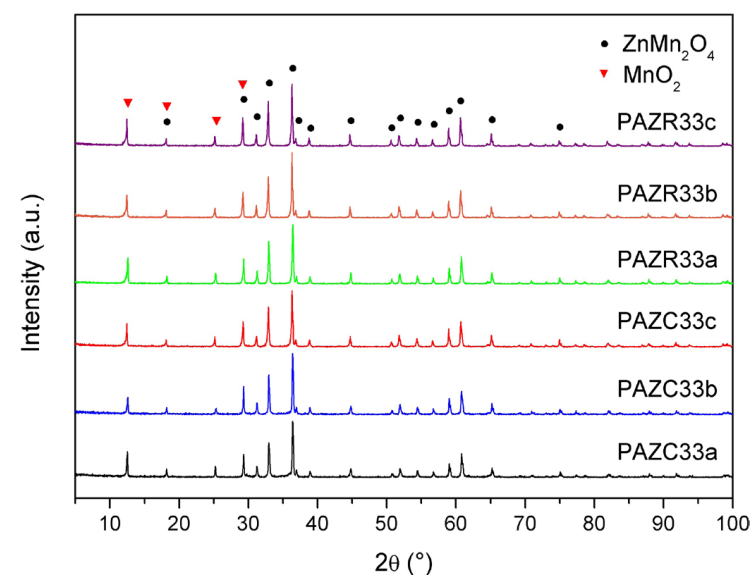

Figure 4. X-ray diffractogram of the PAZC 33 and PAZR33 samples after heat treatment at $1200^{\circ} \mathrm{C}$. The $\mathrm{a}, \mathrm{b}$, or c indices in sample names refer to replicate syntheses.

hetaerolite $\left(\mathrm{ZnMn}_{2} \mathrm{O}_{4}\right)$ compound with a spinel-type structure (JCPDF 24-1133), so that the permanence of the secondary phase $\mathrm{MnO}_{2}$ was observed. There was also a reduction in the relative intensity of the peaks referring to the secondary phase, which was a good indication of the reduction of the 
amount of the same. The formation of intense and defined peaks indicated that the addition of $33 \%$ (in mol) of the commercial zinc oxide and the recovered zinc oxide led to the formation of a higher-crystallinity $\mathrm{ZnMn}_{2} \mathrm{O}_{4}$ phase, a result that can be confirmed by the comparison of the micrographs of the pure material (Figure 3) and the pigments PAZC33 and PAZR33 (Figure 5).

The formation of $\mathrm{ZnMn}_{2} \mathrm{O}_{4}$ and the possible reduction of secondary phase $\mathrm{MnO}_{2}$ for the pigment obtained at $1200^{\circ} \mathrm{C}$ was a very important result since it confirmed the viability of the method used in this work for producing thermally stable pigments without the release of gases which can produce cracks and bubbles in enamel.

The micrographs obtained by FE-SEM of the pigments PAZC33 and PAZR33 are shown in Figure 5A and Figure 5C. The micrographs showed that the addition of commercial zinc oxide and the recovered zinc oxide altered the morphology of the samples, leading to the formation of smaller and more homogeneous particles with crystals of octahedral habit. Based on the $5 \mu \mathrm{m}$ scale, it was possible to observe that all the samples had particles with diameters $<5 \mu \mathrm{m}$, a value considered suitable for application as a ceramic pigment ${ }^{14}$. Concerning its application in paints and polymers, as the maximum particle size limit was smaller (between $0.02 \mu \mathrm{m}$ and $1 \mu \mathrm{m})$, the expected performance for these samples can be reduced without further milling ${ }^{15-17}$.

Figure $5 \mathrm{~B}$ and Figure 5D show the particle size distributions of pigments PAZC33 and PAZR33 after heat treatment at $1200{ }^{\circ} \mathrm{C}$. The PSD analysis revealed that the samples PAZC33 and PAZR33 were composed of particles with diameters between $0.3 \mu \mathrm{m}$ and $65 \mu \mathrm{m}$, with mean particle diameters of $6.39 \mu \mathrm{m}$ and $5.54 \mu \mathrm{m}$, respectively. In this case, it was possible to observe that the addiction of $33 \%$ (in mol) of $\mathrm{ZnO}$ resulted in a reduction in mean particle size when compared to the CAT 1200 samples. This analysis confirms the results obtained by FE-SEM, with average particle sizes below $5 \mu \mathrm{m}$, indicated for application as ceramic pigment ${ }^{14}$. From the data obtained by XRD (Figure 4) and FE-SEM (Figure 5), there is no difference between samples obtained with commercial $\mathrm{ZnO}$ or with recovered $\mathrm{ZnO}$ from the batteries. This is a good answer for the complete recycling of these devices.

Figure 6 shows the digital photo of the inorganic pigments obtained from recycling alkaline batteries. All compositions and replicates are dark brown in color. The a, b, or c indices in sample names refer to replicate syntheses.
A

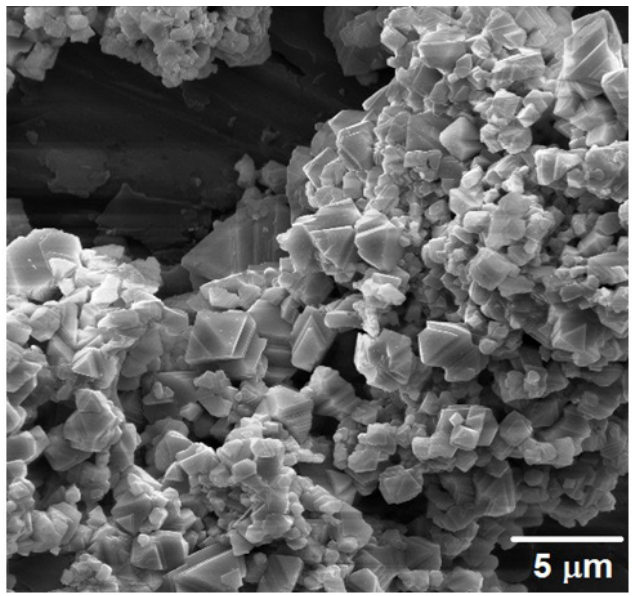

C

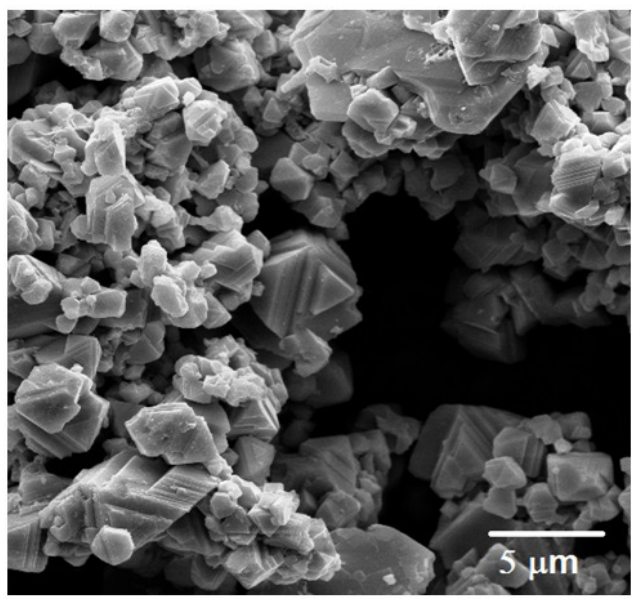

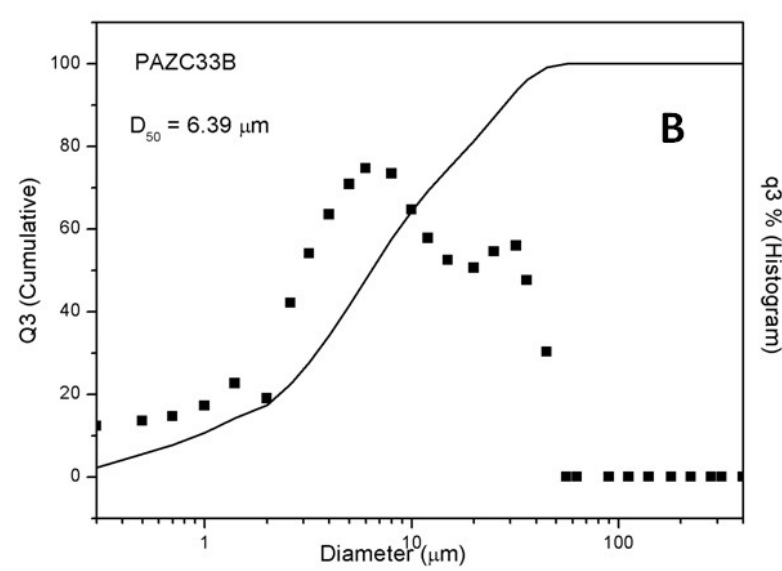

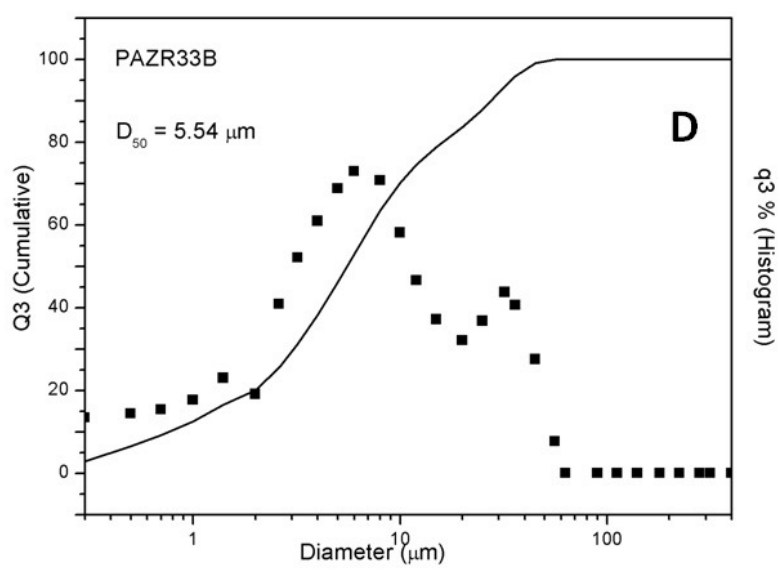

Figure 5. (A) Micrographs obtained by FE-SEM and (B) Particle size distribution of the PAZC $33_{\mathrm{a}}$ sample, after heat treatment at $1200^{\circ} \mathrm{C}$. (C) Micrographs obtained by FE-SEM and (D) Particle size distribution of the PAZR33 sample, after heat treatment at $120{ }^{\circ} \mathrm{C}$. The a, b, or $\mathrm{c}$ indices in sample names refer to replicate syntheses. 


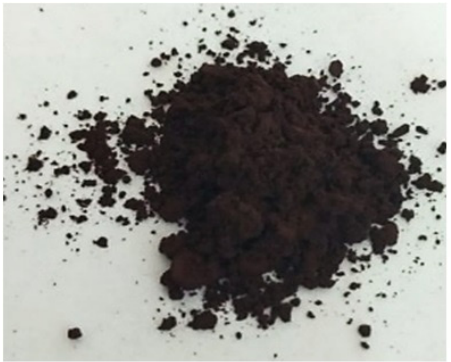

(a)

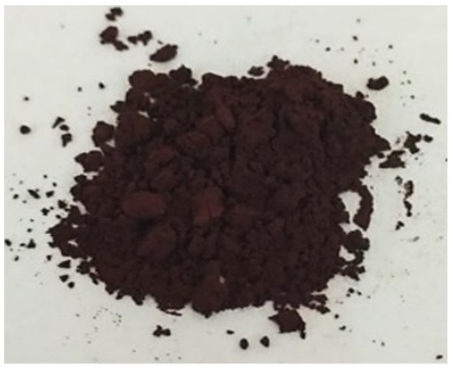

(d)

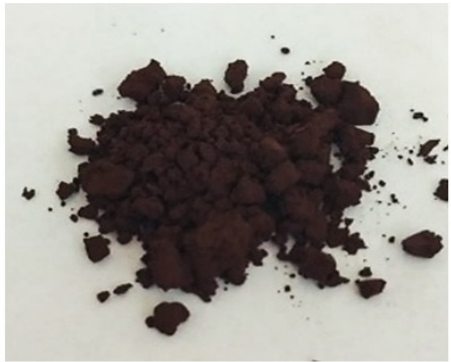

(b)

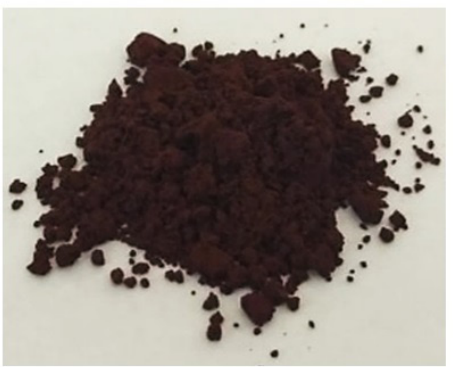

(e)

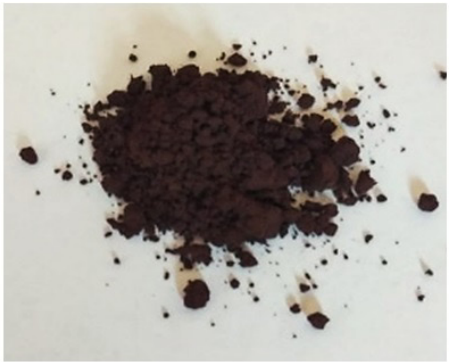

(c)

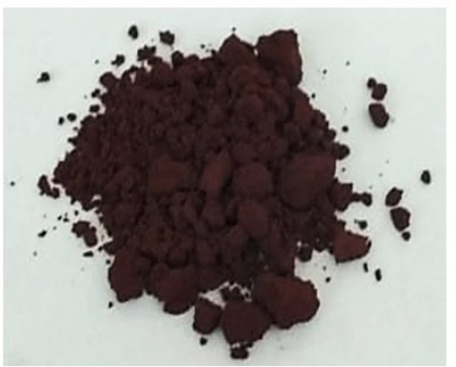

(f)

Figure 6. Photograph of the powder pigments (A) PAZC33 , (B) PAZC33 , (C) PAZC33, (D) PAZR33, (E) PAZR33 $3_{\mathrm{b}}$, and (F) PAZR33. The $\mathrm{a}, \mathrm{b}$, or $\mathrm{c}$ indices in sample names refer to replicate syntheses.

Figure 7 shows the diffuse reflectance spectra of the PAZC 33 and PAZR33 powder pigments after heat treatment at $1200^{\circ} \mathrm{C}$. The $\mathrm{a}, \mathrm{b}$, or $\mathrm{c}$ indices in sample names refer to replicate syntheses.

Reflectance curves indicated that all the pigments did not absorb at specific wavelengths, indicating the contribution of several colors in the final tonality of the powders. The pigments, however, presented a region of higher reflectance between $575 \mathrm{~nm}$ and $800 \mathrm{~nm}$, indicating a greater contribution of yellow, orange and red colors. The contributions of the different colors could be confirmed by the study of their CIE L*a*b* colorimetric coordinates. The colorimetric coordinates of the PAZC33 and PAZR33 powder pigments are shown in Table 2 .

From the analysis of Table 2, it was possible to observe that all the powder pigments presented positive values for the coordinates $\mathrm{a}^{*}$ and $\mathrm{b}^{*}$, confirming a greater contribution of the yellow and red colors. In addition, low values were observed for the $\mathrm{L}^{*}$ coordinate, a result that corroborated with the obtaining of pigments in dark tones, as can be observed in the photography of powder pigments (Figure 6). The pigment samples were synthesized in triplicates. The pigments PAZC33 obtained with commercial $\mathrm{ZnO}$ presented bigger variation in color coordinates between replicates. Both pigments samples have a low delta $\mathrm{E}$ value $\left(\Delta \mathrm{E}_{00}=1.41\right)$ indicating a small color difference for the sensitivity of the human eye.

\subsection{Application of pigments}

Figure 8 shows the result of application of pigments PAZC 33 and PAZR33 in ceramics, paints and polymer. The a, $\mathrm{b}$, or $\mathrm{c}$ indices in sample names refer to replicate syntheses.

The analysis of Figure $8 \mathrm{~A}-\mathrm{F}$ indicated that the ceramic samples enameled with pigments PAZC 33 and PAZR33

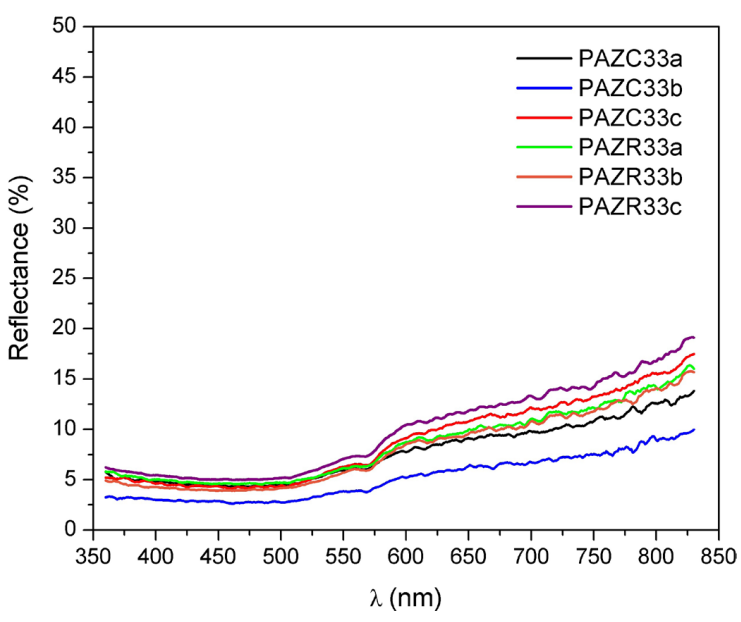

Figure 7. Diffuse reflectance spectra of the PAZC33 and PAZR33 samples after heat treatment at $1200^{\circ} \mathrm{C}$. The $\mathrm{a}, \mathrm{b}$, or $\mathrm{c}$ indices in sample names refer to replicate syntheses.

presented smooth surfaces, with brightness and few defects, indicating that the pigments were not attacked by the frit used in this work. We could observe that all the pigments presented good dispersion in the paints (Figure 8 G-L, even without further milling, simultaneously conferring staining and covering of the surface of the glass slide. As regards staining, the paints were in shades of gray, very similar to each other, resulting from the mixing of the dark pigments with the commercial white paint. Figure $8 \mathrm{M}-\mathrm{R}$ also present the results of the application of PAZC33 and PAZR33 pigments in PMMA staining. All the pigments presented high staining power, resulting in polymers in shades of 
Table 2. CIE L*a*b* colorimetric coordinates of powder pigments PAZC33 and PAZR33. The samples were synthesized in triplicates.

\begin{tabular}{ccccc}
\hline Pigments & $\mathrm{L}^{*}$ & $\mathrm{a}^{*}$ & $\mathrm{~b}^{*}$ & $\Delta \mathrm{E} 00$ \\
\cline { 1 - 4 } PAZC33 & $28.2694 \pm 3.45$ & $7.5718 \pm 1.26$ & $9.0137 \pm 1.61$ & \multirow{2}{*}{1.41} \\
\cline { 1 - 4 } PAZR33 & $30.8452 \pm 1.60$ & $8.9018 \pm 0.59$ & $9.3210 \pm 0.99$ & \\
\hline
\end{tabular}

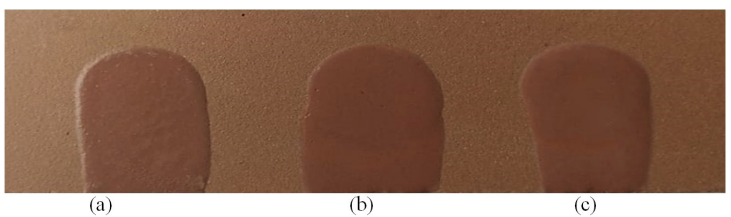

(a) (b)

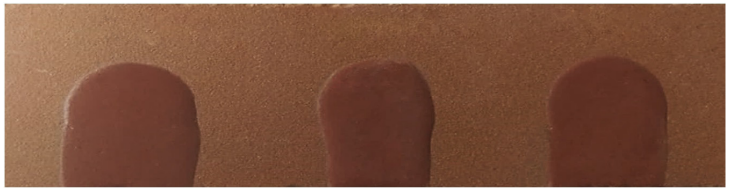
(d) (e) (f)

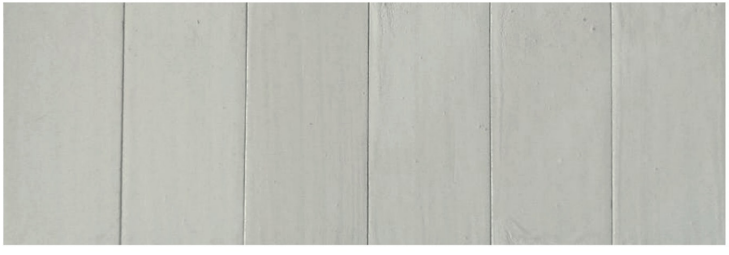

(g) (h) (i) (j) (k) (I)

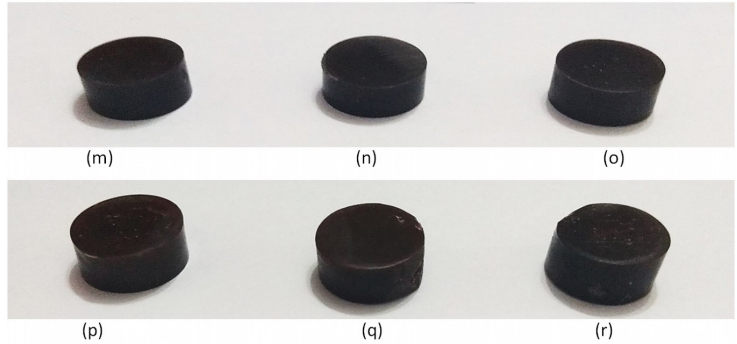

Figure 8. Application of pigments in ceramics: (A) PAZC33, (B) PAZC33, (C) PAZC33, (D) PAZR33, (E) PAZR33, and (F) PAZR33 ; in paints: (G) PAZC33, (H) PAZC33, (I) PAZC33, (J) PAZR33, (K) PAZR33, and (L) PAZR33; in the PMMA: (M) PAZC33, (N) PAZC33, (O) PAZC33, (P) PAZR33, (Q) PAZR33, and (R) PAZR33. The a, b, or c indices in sample names refer to replicate syntheses.

dark brown, very similar to each other. No defects were observed regarding the incompatibility among any of the components of the mixture: polymer, resin, and pigment. The small defects found in the pellets occurred exclusively due to failures in the pressing process, mainly related to the polymerization time and removal of the pellets from the steel mold. The replicates of the synthesis show that all pigments can produce reproducible color in ceramics, paints and polymers.

\section{Conclusion}

The incorporation of the components of spent alkaline batteries allowed the production of spinel-type brown pigments $\mathrm{ZnMn}_{2} \mathrm{O}_{4}$, but with the presence of secondary phases. The results obtained for the pigments with commercial zinc oxide and recovered zinc oxide from battery anodes were very similar to each other, indicating that the commercial zinc oxide could be replaced by the recovered zinc oxide, allowing the synthesis of reproducible pigments exclusively from components of the spent batteries. The samples PAZC33 and PAZR33 with composition $\mathrm{ZnMn}_{2} \mathrm{O}_{4}$ presented good results for application in paints, polymers, and ceramics, obtaining materials of quality and with commercial potential for application as ceramics pigments.

\section{Acknowledgment}

The authors are grateful for the financial support of CAPES. CNPq and Fundação Araucária and for the C-Labmu-UEPG and the physicochemical characterization laboratory of the Materials Engineering Department (DEMA-UEPG) by the analyzes carried out.

\section{References}

1. Gouveia N. Resíduos sólidos urbanos: impactos socioambientais e perspectiva de manejo sustentável com inclusão social. Cien Saude Colet. 2012;17(6):1503-10.

2. Silva RG, Silva CN, Afonso JC. Recovery of manganese and zinc from spent $\mathrm{Zn}-\mathrm{C}$ and alkaline batteries in acidic medium. Quim Nova. 2010;33(9):1957-61.

3. Sayilgan E, Kukrer T, Civelekoglu G, Ferella F, Akcil A, Veglio $\mathrm{F}$, et al. A review of technologies for the recovery of metals from spent alkaline and zinc-carbon batteries. Hydrometallurgy. 2009;97(3-4):158-66.

4. Ferella F, Michelis I, Vegliò F. Process for the recycling of alkaline and zinc-carbon spent batteries. J Power Sources. 2008;183(2):805-11.

5. Bocchi N, Ferracin LC, Biaggio SR. Pilhas e baterias: funcionamento e impacto ambiental. Quím Nova Esc. 2000;11:3-9.

6. Silva BO, Câmara SC, Afonso JC, Neumann R, Alcover Neto A. Série histórica da composição química de pilhas alcalinas e zinco-carbono fabricadas entre 1991 e 2009. Quim Nova. 2011;34(5):812-8.

7. Baba AA, Adekola AF, Bale RB. Development of a combined pyro-and hydro-metallurgical route to treat spent zinc-carbon batteries. J Hazard Mater. 2009;171:838-44.

8. Albuquerque GB, Ballman TJS, Folgueras MV, Prim SR. Síntese de pigmento cerâmico verde com base na estrutura cristalina da wollastonita. Revista Matéria. 2016;21:355-64.

9. Milanez KW, Kniess CT, Bernardin AM, Riella HG, Kuhnen NC. Caracterização de pigmentos inorgânicos à base de Fe, Zn e Cr utilizando resíduo de galvanoplastia como matéria-prima. Ceramica. 2005;51:107-10.

10. Marcello RR, Galato S, Peterson M, Riella HG, Bernardin AM. Inorganic pigments made from the recycling of coal mine drainage treatment sludge. J Environ Manage. 2008;88:1280-4.

11. Fiuza TER, Göttert D, Pereira LJ, Antunes SRM, Andrade AVC, Antunes AC, et al. Production of brown inorganic pigments with spinel structure using spent zinc-carbon batteries. Process Appl Ceram. 2018;4:319-25.

12. Vishnu VS, George G, Divya V, Reddy MLP. Synthesis and characterization of new environmentally benign tantalum-doped $\mathrm{Ce} 0.8 \mathrm{Zr} 0.2 \mathrm{O} 2$ yellow pigments: applications in coloring of plastics. Dyes Pigments. 2009;82(1):53-7.

13. Müller M, Villalba JC, Mariani FQ, Dalpasquale M, Lemos MZ, Huila MFG, et al. Synthesis and characterization of iron 
oxide pigments through the method of the forced hydrolysis of inorganic salts. Dyes Pigments. 2015;120(3):271-8.

14. Monrós G, Badenes JA, García A, Tena MÁ. El color de la cerámica: nuevos mecanismos en pigmentos para los nuevos procesados de la industria cerámica. Spain: Universitat Jaume I; 2003.
15. Drobny JG. Handbook of thermoplastic elastomers. Norwich: William Andrew; 2007.

16. Harris RM. Coloring technology for plastics. Norwich: William Andrew; 1999.

17. Harper CA, Petrie EM. Plastics materials and processes: a concise encyclopedia. New York: John Wiley \& Sons; 2003. 